\title{
A 3D geometric morphometric dataset quantifying skeletal variation in birds
}

\author{
Alexander Bjarnason ${ }^{1 *}$, Roger Benson ${ }^{1 *}$ \\ ${ }^{1}$ Department of Earth Sciences, University of Oxford, South Parks Road, Oxford, OX1 3AN \\ *Corresponding authors: alex.bjarnason@earth.ox.ac.uk, roger.benson@earth.ox.ac.uk
}

\begin{abstract}
Macroevolution is integral to understanding the patterns of the diversification of life. As the life sciences increasingly use big data approaches, large multivariate datasets are required to test fundamental macroevolutionary hypotheses. In vertebrate evolution, large datasets have been created to quantify morphological variation, largely focusing on particular areas of the skeleton. We provide a landmarking protocol to quantify morphological variation in skeletal elements across the head, trunk, hindlimb and forelimb using 3-dimensional landmarks and semilandmarks, and present a large pan-skeletal database of bird morphology for 149 taxa across avian phylogeny using CT scan data. This large collection of 3D models and geometric morphometric data is open access and can be used in the future for new research, teaching and outreach.
\end{abstract}

Keywords: birds, geometric morphometrics, macroevolution, morphology, skeleton

Submitted:2020-06-26, published online:2021-02-09. https://doi.org/10.18563/journal.m3.125.

SI Data: https://doi.org/10.18563/journal.m3.125.supp.data

\section{INTRODUCTION}

Evolution can be studied from two perspectives: microevolution, the processes that create biological variation at the intraspecific level, and macroevolution, the patterns of variation between groups at the interspecific level (Hautmann, 2020). In the broadest sense, macroevolution concerns the evolution of differences between groups, in species richness and phenotypic disparity. These evolved through extended spans of deep-time, and gave rise to the diversity of life on Earth. Macroevolution encompasses areas of research at the intersection of ecology, genetics, developmental biology and palaeobiology.

Key macroevolutionary questions seek to address variation in the tempo (rate) and mode (pattern) of evolution along lineages (Simpson, 1944; Gingerich, 1983; Schluter, 2000), and the extent to which patterns of taxonomic and phenotypic diversity are explained by speciation, extinction (Jablonski, 2005; Ezard et al., 2011), competition (e.g. Jablonski, 2008; Silvestro et al., 2015; Ezard and Purvis, 2016) and opportunity (e.g. Etienne and Haegeman, 2012). Macroevolutionary theory encompasses inter-disciplinary hypotheses in the biological sciences, such as adaptive radiations (Simpson, 1953; Harmon et al., 2003, 2010; Losos and Mahler, 2010; Yoder et al., 2010), functional adaptation (e.g. Vrba, 1983; Hansen, 1997, 2012), patterns of integration and modularity (Olson and Miller, 1952; Cheverud, 1982; Goswami, 2006; Klingenberg, 2010; Klingenberg and Marugán-Lobón, 2013), innovation and evolvability (Vermeij, 1973). Considerable recent progress on these topics results from the development of powerful quantitative approaches, particularly in geometric morphometrics and phylogenetic comparative methods (e.g. Pennell and Harmon, 2013; Garamszegi, 2014; Adams and Collyer, 2019).

$\begin{array}{ll}\text { Model Id. } & \begin{array}{l}\text { Description } \\ \text { mandible }\end{array} \\ \text { FMNH336751_M3\#562 } & \text { right coracoid } \\ \text { FMNH336751_M3\#563 } & \text { right scapula } \\ \text { FMNH336751_M3\#564 } & \text { left carpometacarpus* } \\ \text { FMNH336751_M3\#561 } & \text { right tarsometatarsus } \\ \text { FMNH336751_M3\#565 } & \text { sternum } \\ \text { FMNH336751_M3\#566 } & \text { stint } \\ \text { FMNH336751_M3\#567 } & \text { left femur* } \\ \text { FMNH336751_M3\#568 } & \text { skull } \\ \text { FMNH336751_M3\#569 } & \text { left humerus* } \\ \text { FMNH336751_M3\#570 } & \text { synsacrum } \\ \text { FMNH336751_M3\#571 } & \text { left radius * } \\ \text { FMNH336751_M3\#572 } & \text { left tibiotarsus* } \\ \text { FMNH336751_M3\#573 } & \text { left ulna* }\end{array}$

Table 1. One of the specimens, FMNH 336751 (Menura novaehollandiae, the superb lyrebird), is presented here. Sets of 3D landmarks and semi-landmarks have been digitized on the different bones listed. Collection: Field Museum of Natural History, Chicago, USA. The 3D models and CT scans of the 149 specimens related to this project can be downloaded at MorphoSource (https://www.morphosource.org/pro jects/00000C420). *: these 3D models are displayed as mirror images in MorphoMuseuM 3D viewer.

The life sciences have entered an era of big data, in which fundamental questions can increasingly be addressed with large datasets. This is also true of phenotypic macroevolution (e.g. Wilman et al., 2014 [ecological traits]; Pigot et al., 2020 [external traits]), an area that was traditionally approached from a qualitative standpoint or using limited characterisations of the traits of organisms such as linear measurements, body mass estimates, or studies of skeletal parts such as the skull or mandible (e.g. Alroy, 1998; Livezey and Zusi, 2007; Nudds et al., 2007; 


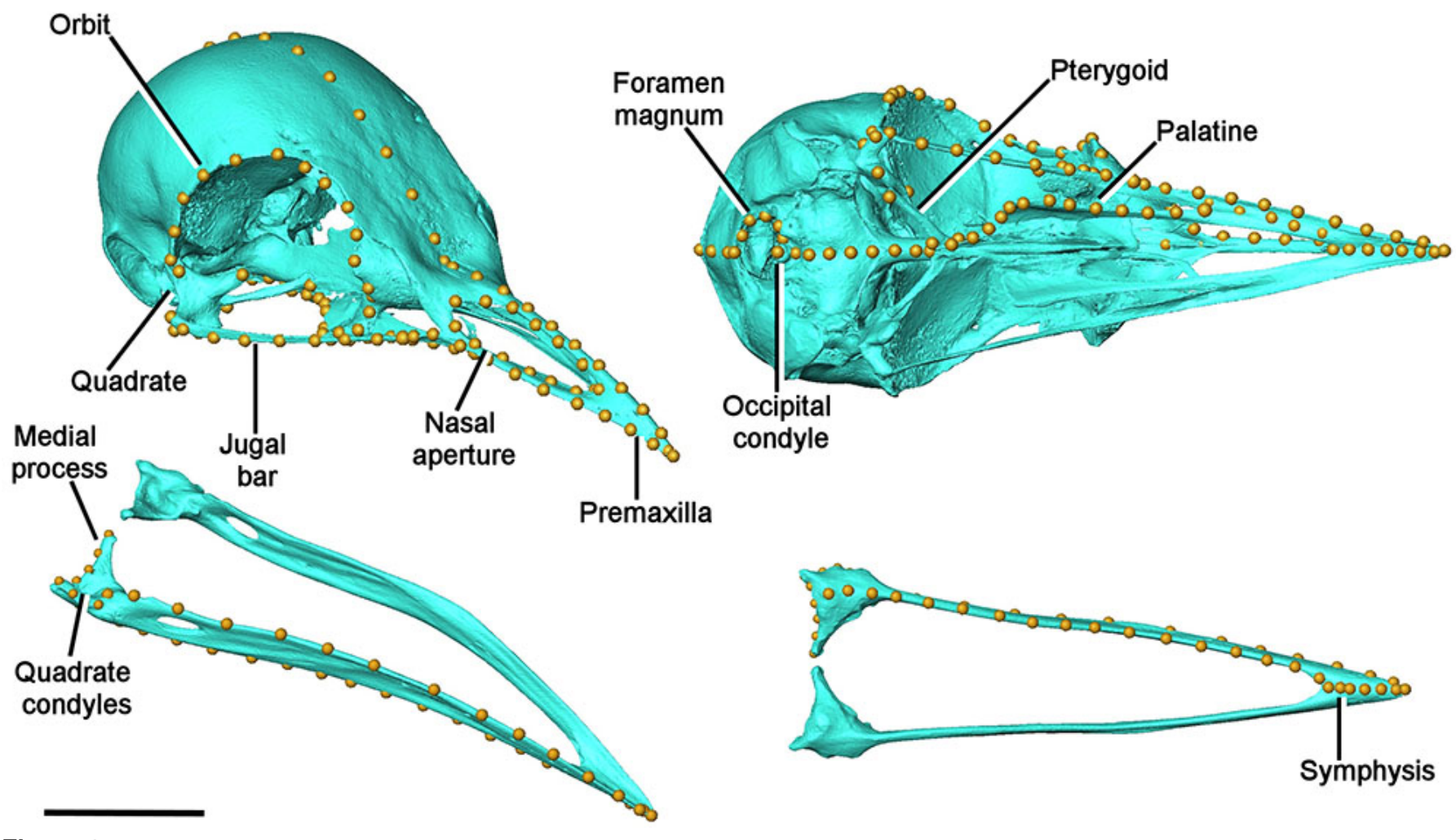

Figure 1. Head landmarks and semilandmarks shown on the skull and mandible of Menura novaehollandiae (FMNH 336751). The skull (A) in dorsolateral (left) and ventral (right) views, and mandible (B) in dorsolateral (left) and ventral (right) views. Scale bar equals $20 \mathrm{~mm}$.

Cooper and Purvis, 2010; Venditti et al., 2011). Phenotypic data assembly has been accelerated by technologies that allow rapid 3D digitisation of morphology (e.g. Davies et al. 2017). Improved access to CT scanning and high-resolution handheld scanners means researchers can make accurate 3-dimensional (3D) models of external morphology, including study skins allowing for example quantification of the head in snakes and rhamphotheca in birds (Fabre et al., 2016; Segall et al., 2016; Cooney et al., 2017; Segall, Herrel and Godoy-Diana, 2019) and hard tissues such as vertebrate bones (Felice and Goswami, 2018; Watanabe et al., 2019; Bardua et al., 2020; Coombs et al., 2020; Fabre et al., 2020; Fischer et al., 2020). High resolution scans can be used to make large morphological datasets quantifying variation with geometric morphometric methods, providing opportunities for large, quantitative datasets to address central macroevolutionary questions and push the frontier of macroevolutionary research (e.g. Corfield et al., 2015; Cooney et al., 2017; Felice and Goswami, 2018; Watanabe et al., 2019; Bardua et al., 2020; Navalón et al., 2020; Paluh et al., 2020). Macroevolutionary studies have so far enriched our understanding of vertebrate cranial evolution (e.g. Bhullar et al., 2012; Felice and Goswami, 2018; Arbour et al., 2019; Paluh et al., 2020) and that of other anatomical units (e.g. Botelho et al., 2014; Arnold et al., 2017; Shatkovska et al., 2018; Serrano et al., 2020). However, organisms are generally complex, comprising multiple interacting parts, and few studies have quantified wider aspects of skeletal variation beyond studies of integration (e.g. Bell et al., 2011; Dececchi and Larsson, 2013; Fabre et al., 2014;
Heers and Dial, 2015; Martín-Serra et al., 2015; Botton-Divet $e t$ al., 2016; Wright et al., 2016; Hanot et al., 2018; Randau and Goswami, 2018; Michaud et al., 2020).

Until recently, the expense and difficulty of accessing CT scanning and relative lack of postcranial material in natural history collections has created gaps in our understanding of skeletal macroevolution that leads to key questions: How universal are evolutionary patterns inferred from single bones to the whole organism? How does functional or developmental integration among the components of organisms structure macroevolutionary patterns? And how does the influence of ecomorphological adaptation vary among parts of the organism?

We quantified morphology across 13 skeletal units using a novel geometric morphometric landmarking scheme (see Supplementary 1-3, available at https://doi.org/10.18563/journal.m3 .125.supp.data; see also Table 1.): the head (skull and mandible; see Fig. 1), trunk (scapula, coracoid, sternum and synsacrum; see Fig. 2), forelimb (humerus, ulna, radius, carpometacarpus; see Fig. 3) and hindlimb (femur, tibiotarsus and tarsometatarsushumerus; see Fig. 4). We present a pan-skeletal database of birds (Aves) skeletal morphology comprising CT scans of the entire skeleton of 149 species, of broad phylogenetic scope (https://www.morphosource.org/projects/00000C420). This is the basis of our in-preparation macroevolutionary investigations, and we anticipate that our 3D datasets will be of value to other researchers. Birds are one of the most speciose vertebrate groups with over 10,000 extant species (Gill et al. 2020). They are feathered, have lightweight bills and no teeth, small 

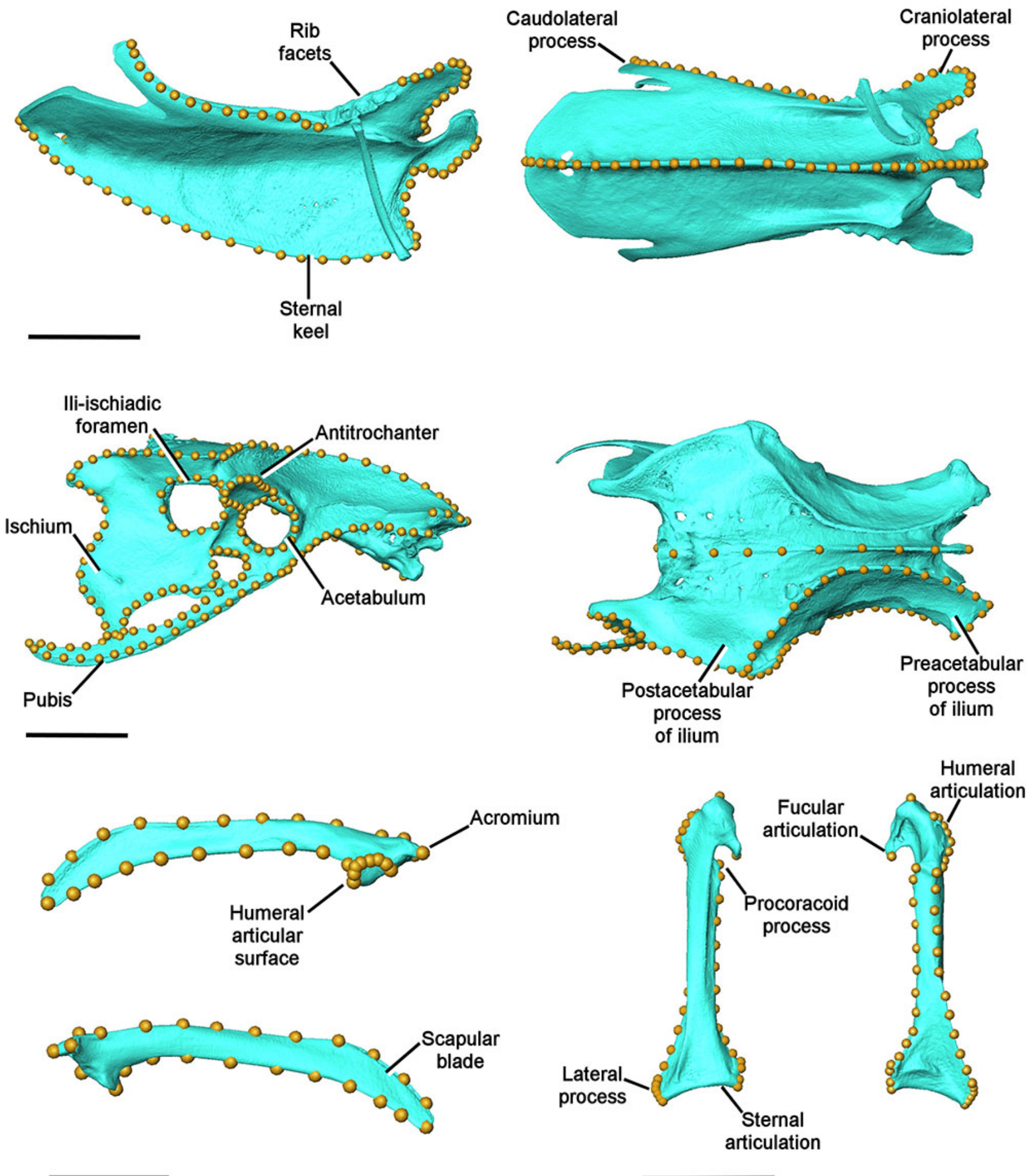

Figure 2. Trunk landmarks and semilandmarks shown on the synsacrum, scapula and coracoid of Menura novaehollandiae (FMNH 336751 ). The sternum (A) in lateral (left) and ventral (right) views, synsacrum (B) in lateral (left) and dorsal (right) views, scapula (C) in lateral right (top) and lateral left (bottom) views, and coracoid (D) in ventral (left) and dorsal (right) views. Scale bars equal to $20 \mathrm{~mm}$. 


$\begin{array}{lll}\text { Skeletal element } & \begin{array}{l}\text { Number of } \\ \text { points for } \\ \text { minimum "min”" } \\ \text { configuration }\end{array} & \begin{array}{l}\text { Number of } \\ \text { points for } \\ \text { “mean” } \\ \text { configuration }\end{array} \\ \text { Skull } & 158 & 420 \\ \text { Mandible } & 43 & 109 \\ \text { Sternum } & 67 & 383 \\ \text { Synsacrum } & 208 & 510 \\ \text { Scapula } & 31 & 71 \\ \text { Coracoid } & 33 & 71 \\ \text { Humerus } & 79 & 145 \\ \text { Radius } & 10 & 20 \\ \text { Ulna } & 28 & 54 \\ \text { Carpometacarpus } & 77 & 166 \\ \text { Femur } & 62 & 128 \\ \text { Tibiotarsus } & 52 & 97 \\ \text { Tarsometatarsus } & 57 & 118\end{array}$

Table 2. Number of resampled landmark points for each skeletal element showing the number of points for the minimum ("min") configuration (left) and "mean" configuration (right).

body sizes, pneumatised bones and highly fused skeletons, are mostly capable of flight, and are adapted for a wide range of environments with large variation in morphology, behaviour and ecology (Proctor and Lynch, 1993; Wilman et al. 2014). The past decade has seen major advances in our understanding of avian macroevolution (e.g. Jetz et al., 2012; Jarvis et al., 2014; Prum et al., 2015; Bright et al., 2016; Cooney et al., 2017; Felice and Goswami, 2018; Felice et al., 2019; Oliveros et al., 2019; Navalón et al., 2020; Pigot et al., 2020), and future investigations of skeletal morphology using CT scan data will go far beyond what we have been able to achieve so far.

\section{METHODS}

Our dataset includes 149 genera belonging to 106 families and 33 orders, representing most major avian groups (Supplementary 1). These taxa, or close relatives that can be used as proxies, are all present in the Prum et al. (2015) avian molecular phylogeny, which provides a framework for phylogenetic comparative methods of our dataset (Supplementary 1). Our dataset was assembled by lab-based micro-CT scanning of specimens from major museum collections: Natural History Museum of London, bird collection, Tring, UK (NHMUK); University of Cambridge Museum of Zoology, Cambridge, UK (UMZC); University of Michigan Museum of Zoology, Ann Arbor, Michigan, USA (UMMZ); Field Museum of Natural History, Chicago, USA (FMNH); University of Oxford Museum of Natural History, Oxford, UK (OUMNH); and Yale Peabody Museum, New Haven, Connecticut, USA (YPM). We also used multiple CT scanning facilities: including Nikon Metrology XT H 225 ST High Resolution CT Scanner systems at (A) School of Life Sciences, University of Bristol, Bristol UK; (B) Computed Tomography facility, Natural History Museum, London, UK (C) Cambridge Biotomography Centre, Cambridge, UK; and (D) Earth and Environmental Sciences CT facility, University of Michigan, Ann
Arbor, USA; and (E) Yale University's Chemical and Biophysical Instrumentation Centre (CBIC); and custom-built dual tube CT scanner from General Electric (phoenix v-tome-x s) at the PaleoCT facility of University of Chicago, Chicago, USA. Metadata for each scan including specimen repository, CT facility, and scan settings are available at the Morphosource page associated with this publication. CT scans were initially reconstructed as 16-bit tomograms. Pre-processing steps including stitching of multiple scan volumes to single image volumes, cropping image volume, and conversion of image volumes from 16-bit to 8-bit were carried out using ImageJ 1.5 (Schneider et al., 2012). Volume data were imported into Avizo 9.3 (Thermo Fisher Scientific, Zuse Institute Berlin) for segmentation and exported as PLY files. The resulting 8-bit image volumes, 3D surfaces and scan metadata are available via Morphosource (https://www.morphosource.org/projects/00000C420).

Procrustes-based geometric morphometric data was collected in Avizo 9.3, using anatomical landmarks and semilandmark series ((Gower, 1975; Rohlf and Slice, 1990; Rohlf and Marcus, 1993; Adams, Rohlf and Slice, 2004, 2013; Bhullar et al., 2012), Figs 1-4). Detailed landmark descriptions and figures are provided in Supplementary 2. Anatomical consideration leading to landmark specification was based on multiple studies of avian morphology (Baumel and Witmer, 1993; Zusi, 1993; Livezey and Zusi, 2006; Kulemeyer et al., 2009; Tokita et al., 2017) and our own observations. Anatomical terms of orientation follow Clark (1993) using cranial (or rostral when referring to the head) and caudal rather than anterior or posterior. Summary landmark and semi-landmark configurations with major anatomical structures labelled are shown here using Menura novaehollandiae (FMNH 336751) for the head (Fig. 1), trunk (Fig. 2), forelimb (Fig. 3) and hindlimb (Fig. 4). Semilandmarks were used to characterise curves, but not surfaces, and curves were initially characterised using variable numbers of points, according to structural complexity. They were then resampled to equal numbers of evenly spaced points in the data presented here for morphometric analysis. Resampling was conducted according to two different criteria: (1) The minimum ("min") criterion, in which semilandmarks were resampled so that each curve contained the same number of points equal to that of the specimen with the fewest number of points for that series; and (2) The "mean" criterion, in which semilandmarks were resampled so that each contained the mean number of points across all specimens (Table 2). Due to the frequency of specimens having damage to either the left or right part of a skeletal element, our overall dataset samples a mix of left- and right-side elements, with all left sided landmarks reflected to simulate right-sided elements prior to Generalized Procrustes Analysis (GPA). Just one of each skeletal element was landmarked per specimen to maximise the number of taxa that were sampled during the data collection phase of our project, and this one-sided landmarking approach is accurate at quantifying size and shape at the macroevolutionary scale (Cardini 2016, 2017). Due to expediency and maximising our time for data 

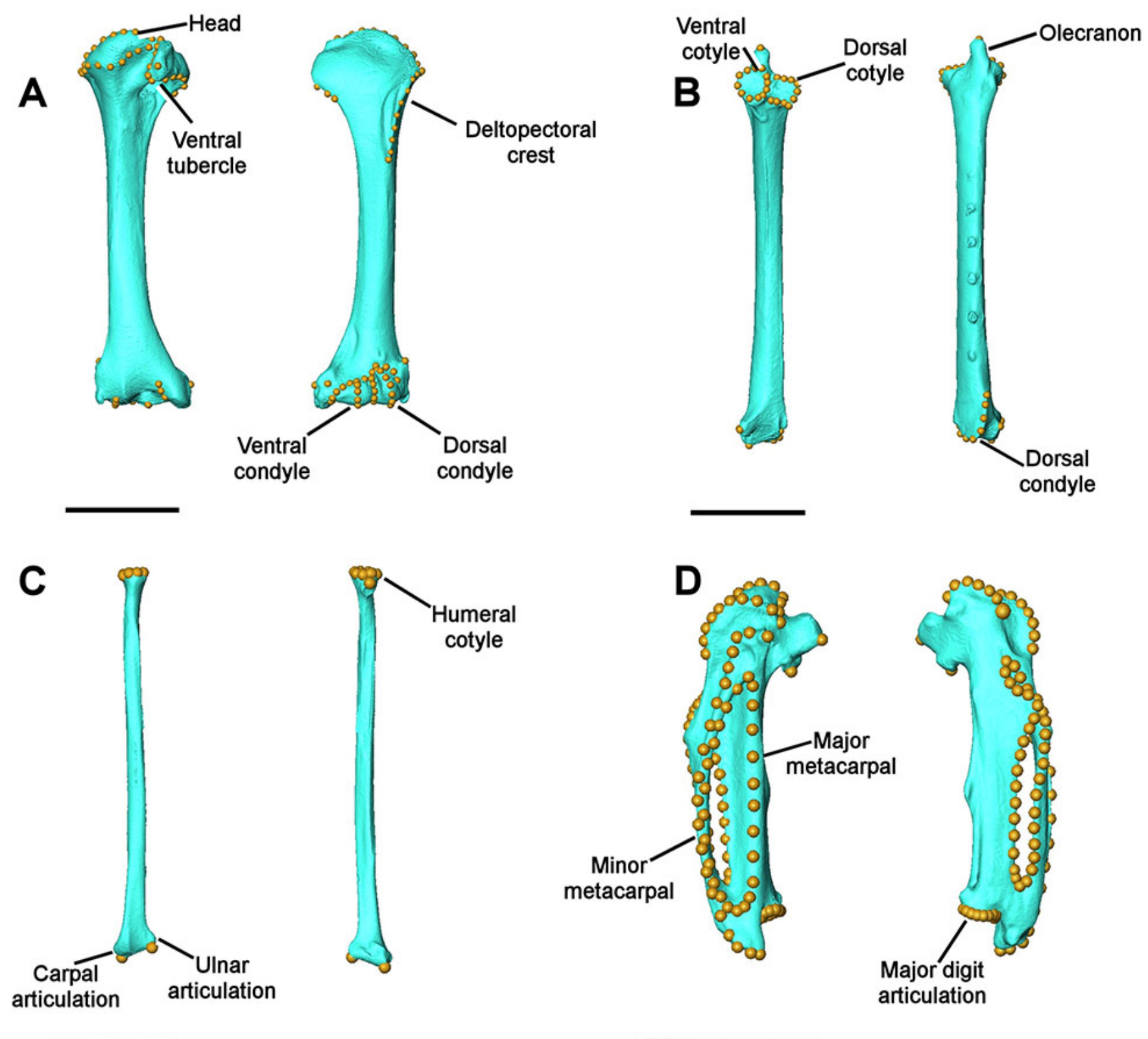

Figure 3. Forelimb landmarks and semilandmarks shown on the humerus, ulna, radius and carpometacarpus of Menura novaehollandiae (FMNH 336751). The humerus (A) in caudal (left) and cranial (right) views, ulna (B) in cranial (left) and caudal (right) views, radius (C) in cranial (left) and caudal (right) views, and carpometacarpus (D) in ventral (left) and dorsal (right) views. Scale bars equal $20 \mathrm{~mm}$. 
collection, we also landmarked only one side of each bilaterallysymmetrical element. Our data are therefore appropriate only for analyses that do not seek to analyse bilateral symmetry. Cardini $(2016,2017)$ noted that when sampling one half of a bilaterally symmetrical skeletal element with midline landmarks, it is advisable to mirror the missing landmarked side prior to GPA for increased accuracy, as landmarks perpendicular to the midline can be erroneously misplaced during the GPA. As a result, for bilaterally symmetrical skeletal regions of the skull, sternum and synsacrum, one half of the structure was landmarked, including along the midline, in each specimen and the collected bilateral landmarks were mirror reflected for use in the GPA. These reflected elements should not be considered for analysis of bilateral symmetry.

Data files containing our landmarks are presented in CSV and TPS formats in Supplementary 3, in a form that is readily analysable using functions in geomorph version 3.2.1 (Adams et al. 2020) and can be read into alternative geometric morphometric software such as MorphoJ. This includes relevant metadata such as matrices specifying tangent vectors for sliding semilandmarks, vectors of point colours specifying membership to semilandmark series, and original input data (i.e. with variable numbers of semilandmark points among specimens).

\section{DISCUSSION}

We present a large, broad-scope, multi-element geometric morphometric dataset of avian skeletal morphology. This dataset can be used to investigate some of the major questions in vertebrate and avian macroevolution including patterns of evolution across the skeleton, the contribution of modularity and integration to skeletal variation, and the relationship between size and shape (allometry) among and within parts of the skeleton. The large 3D database will be useful for studies of functional morphology and anatomy, including comparative osteology and phylogenetics, and complements other publically available avian databases including those on Phenome10k (https: //www.phenome10k.org/), Aves 3D (https://www.aves3d.org/) and the major oVert scanning project housed on morphosource (https://www.morphosource.org/). Our CT scan data is also available to be used for investigating aspects of morphology we have not included in our data collection, such as finite element analysis, cross-sectional analysis of bone structure and microstructure, musculoskeletal and range of motion models, bioinspiration, bilateral symmetry, cranial endocasts and inner ear morphology. Our landmark and semi-landmark configurations should be considered as an initial proposal that is useful for investigating large-scale aspects of avian skeletal evolution. More detailed schemes, including surface semilandmarks or high-density landmarking (e.g. Felice and Goswami, 2018; Bardua et al., 2019b, 2019a; Goswami et al., 2019; Watanabe et al., 2019) may add further to our understanding of this topic in future, or in detailed studies of local regions of the avian skeleton.
As recently recommended (Davies et al., 2017), our data is open access in order to improve reproducibility and encourage the reuse of data and models in new studies. Bird morphology is fascinating to researchers and the $3 \mathrm{D}$ models associated with our dataset have clear utility in new avenues of research, and we also hope they can also be used in teaching and outreach.

\section{ACKNOWLEDGEMENTS}

This work was funded by the European Union's Horizon 2020 research and innovation program 2014-2018 under grant agreement 677774 (European Research Council [ERC] Starting Grant: TEMPO). For access to specimens, we thank Judith White and Jo Cooper (NHMUK), Janet Hinshaw (UMMZ), Mathew Lowe and Mike Brooke (UMZC), Mark Carnall and Eileen Westwig (OUMNH), Kristof Zyskowski (YPM), Ben Marks and John Bates (FMNH). For access to CT scanning facilities we thank Ketura Smithson (Cambridge Biotomography Centre), Tom Davies, Ben Moon and Liz Martin-Silverstone (University of Bristol), Vincent Fernandez (Natural History Museum), April Neander and Zhe-Xi Luo (University of Chicago PaleoCT), and Matt Friedman (University of Michigan). For technical support of segmentation we thank Andrzej Wolniewicz, Stephanie Wright, Stephanie Poindexter, Elizabeth Griffiths, Serjoscha Evers and Andrew Orkney. For assistance with Morphosource we thank Julie Winchester and Doug Boyer.

\section{BIBLIOGRAPHY}

Adams D.C., Collyer M.L., 2019. Phylogenetic Comparative Methods and the Evolution of Multivariate Phenotypes. Annual Review of Ecology, Evolution, and Systematics 50, 405-425. https://doi.org/10.1146/annurev-ecolsys-110218-024555

Adams D. C., Rohlf F. J., Slice D. E., 2004. Geometric morphometrics: ten years of progress following the 'revolution.' Italian Journal of Zoology 71, 5-16. https://doi.org/10.1080/11 250000409356545

Adams D. C., Rohlf F. J., Slice D. E., 2013. A field comes of age: geometric morphometrics in the 21 st century. Hystrix 24 , 7-14. https://doi.org/10.4404/hystrix-24.1-6283

Alroy J., 1998. Cope's rule and the dynamics of body mass evolution in North American fossil mammals. Science 280, 731-734. https://doi.org/10.1126/science.280.5364.731

Arbour J.H., Curtis A.A., Santana S.E., 2019. Signatures of echolocation and dietary ecology in the adaptive evolution of skull shape in bats. Nature Communications 10, 1-13. https: //doi.org/10.1038/s41467-019-09951-y

Arnold P., Amson E., Fischer M.S., 2017. Differential scaling patterns of vertebrae and the evolution of neck length in mammals. Evolution 71, 1587-1599. https://doi.org/10.1111/evo.1 3232

Bardua C., Felice R.N., Watanabe A., Fabre A.C., Goswami A., 2019a. A practical guide to sliding and surface semilandmarks in morphometric analyses. Integrative Organismal Biology 1, obz016. https://doi.org/10.1093/iob/obz016 

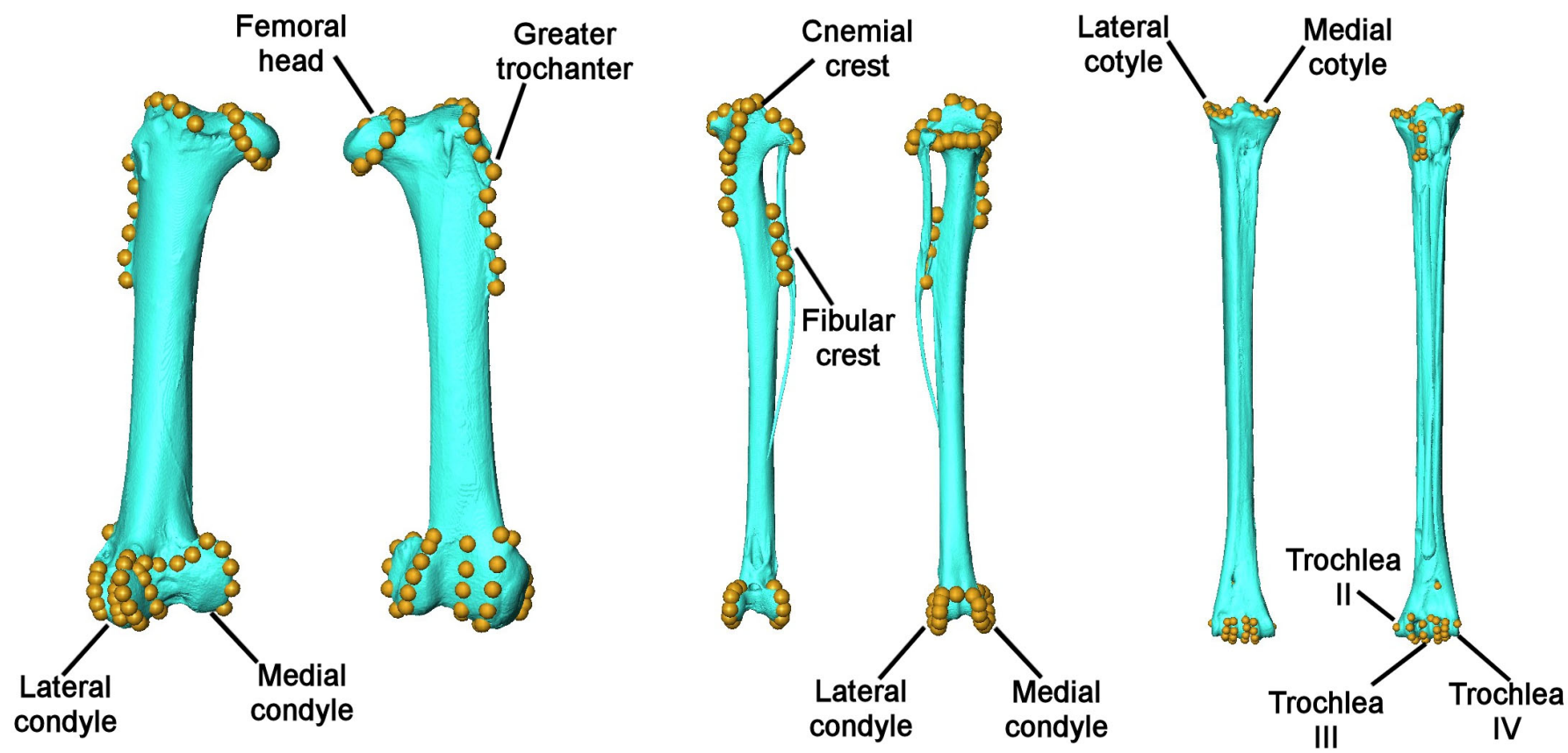

Figure 4. Hindlimb landmarks, semilandmarks shown on the femur, tibiotarsus and tarsometatarsus of Menura novaehollandiae (FMNH 336751 ). The femur (A) in caudal (left) and cranial (right) views, tibiotarsus (B) in cranial (left) and caudal (right) views, and tarsometatarsus (C) in dorsal (left) and plantar (right) views. Scale bars equal $20 \mathrm{~mm}$.

Bardua C., Wilkinson M., Gower D. J., Sherratt E., Goswami A., 2019b. Morphological evolution and modularity of the caecilian skull. BMC Evolutionary Biology 19, 30. https: //doi.org/10.1186/s12862-018-1342-7

Bardua C., Fabre A.C., Bon M., Das K., Stanley E. L., Blackburn D. C., Goswami A., 2020. Evolutionary integration of the frog cranium. Evolution 74, 6. https://doi.org/10.1111/evo.13984

Baumel J. J., Witmer L., 1993. Osteologia; p. 45-132. In: Baumel J.J., King J.E., Breazile J.E., Evans H.E., Vanden Berge J.C., (Eds), Handbook of Avian Anatomy: Nomina Anatomica Avium, 2nd Edition. Nuttall Ornithological Club, Cambridge, pp. 45-132.

Bell E., Andres B., Goswami A., 2011. Integration and dissociation of limb elements in flying vertebrates: a comparison of pterosaurs, birds and bats. Journal of Evolutionary Biology 24, 2586-2599. https://doi.org/10.1111/j.1420-9101.2011.02381.x

Bhullar B.A.S., Marugán-Lobón J., Racimo F., Bever G.S., Rowe T.B., Norell M.A., Abzhanov A., 2012. Birds have paedomorphic dinosaur skulls. Nature 487, 223-226. https: //doi.org/10.1038/nature11146

Botelho J. F., Ossa-Fuentes L., Soto-Acuña S., Smith-Paredes D., Nuñez-León D., Salinas-Saavedra M., Ruiz-Flores M., Vargas A.O., 2014. New developmental evidence clarifies the evolution of wrist bones in the dinosaur-bird transition. PLoS Biology 12, e1001957. https://doi.org/10.1371/journal.pbio. 1001957

Botton-Divet L., Cornette R., Fabre A.-C., Herrel A., Houssaye
A., 2016. Morphological analysis of long bones in semi-aquatic mustelids and their terrestrial relatives. Integrative and Comparative Biology 56, 1298-1309. https://doi.org/10.1093/icb/ic W 124

Bright J. A., Marugán-Lobón J., Cobb S.N., Rayfield E.J., 2016. The shapes of bird beaks are highly controlled by nondietary factors. Proceedings of the National Academy of Sciences 113, 5352-5357. https://doi.org/10.1073/pnas.1602683113

Cardini, A., 2016. Lost in the other half: improving accuracy in geometric morphometric analyses of one side of bilaterally symmetric structures. Systematic Biology 65, 1096-1106. https: //doi.org/10.1093/sysbio/syw043

Cardini, A., 2017. Left, right or both? Estimating and improving accuracy of one-side-only geometric morphometric analyses of cranial variation. Journal of Zoological Systematics and Evolutionary Research 55, 1-10. https://doi.org/10.1111/jzs.1 2144

Cheverud J. M., 1982. Phenotypic, genetic, and environmental morphological integration in the cranium. Evolution 36, 499-516. https://doi.org/10.2307/2408096

Clark Jr G.A., 1993. Anatomia topographica externa. In: Baumel J.J., King J.E., Breazile J.E., Evans H.E., Vanden Berge J.C., (Eds), Handbook of Avian Anatomy: Nomina Anatomica Avium, 2nd Edition. Nuttall Ornithological Club, Cambridge, pp. 7-16.

Coombs E. J., Clavel J., Park T., Churchill M., Goswami A., 2020. Wonky whales: the evolution of cranial asymmetry in 
cetaceans. BMC Biology 18,1-24. https://doi.org/10.1186/s12 915-020-00805-4

Cooney C. R., Bright J.A., Capp E.J.R., Chira A.M., Hughes E.C., Moody C.J.A., Nouri L.O., Varley Z.K., Thomas G.H., 2017. Mega-evolutionary dynamics of the adaptive radiation of birds. Nature 542, 344-347. https://doi.org/10.1038/nature21 074

Cooper N., Purvis A., 2010. Body size evolution in mammals: complexity in tempo and mode. The American Naturalist 175, 727-738. https://doi.org/10.1086/652466

Corfield J. R., Price K., Iwaniuk A.N., Gutierrez-Ibañez C., Birkhead T., Wylie D.R., 2015. Diversity in olfactory bulb size in birds reflects allometry, ecology, and phylogeny. Frontiers in Neuroanatomy 9, 102. https://doi.org/10.3389/fnana.2015.001 02

Davies T. G., et al. 2017. Open data and digital morphology. Proceedings of the Royal Society B: Biological Sciences 284, 20170194. https://doi.org/10.1098/rspb.2017.0194

Dececchi T.A., Larsson H.C.E., 2013. Body and limb size dissociation at the origin of birds: uncoupling allometric constraints across a macroevolutionary transition. Evolution 67, 2741-2752. https://doi.org/10.1111/evo.12150

Etienne R.S., Haegeman B., 2012. A conceptual and statistical framework for adaptive radiations with a key role for diversity dependence. The American Naturalist 180, E75-E89. https: //doi.org/10.1086/667574

Ezard T.H.G., Aze T., Pearson P.N., Purvis A., 2011. Interplay between changing climate and species' ecology drives macroevolutionary dynamics. Science 332, 349-351. https: //doi.org/10.1126/science.1203060

Ezard T.H.G., Purvis A., 2016. Environmental changes define ecological limits to species richness and reveal the mode of macroevolutionary competition. Ecology Letters, 19, 899-906. https://doi.org/10.1111/ele.12626

Fabre A.-C., Bardua C., Bon M., Clavel J., Felice R.N., Streicher J.W., Bonnel J., Stanley E. L., Blackburn D. C., Goswami A., 2020. Metamorphosis shapes cranial diversity and rate of evolution in salamanders. Nature Ecology \& Evolution 4, 1129-1140. https://doi.org/10.1038/s41559-020-1225-3

Fabre A.-C., Bickford D., Segall M., Herrel A., 2016. The impact of diet, habitat use, and behaviour on head shape evolution in homalopsid snakes. Biological Journal of the Linnean Society 118, 634-647. https://doi.org/10.1111/bij.12753

Fabre A.-C., Goswami A., Peigné S., Cornette R., 2014. Morphological integration in the forelimb of musteloid carnivorans. Journal of Anatomy 225, 19-30. https://doi.org/10.1111/joa.1 2194

Felice R.N., Goswami A., 2018. Developmental origins of mosaic evolution in the avian cranium. Proceedings of the National Academy of Sciences 115, 555-560. https://doi.org/ 10.1073/pnas. 1716437115
Felice R.N., Tobias J.A., Pigot A.L., Goswami A., 2019. Dietary niche and the evolution of cranial morphology in birds. Proceedings of the Royal Society B 286, 20182677. https: //doi.org/10.1073/pnas.1716437115

Garamszegi L.Z., 2014. Modern Phylogenetic Comparative Methods and Their Application in Evolutionary Biology: Concepts and Practice. Springer. https://doi.org/10.1007/978-3662-43550-2

Gingerich P., 1983. Rates of evolution: effects of time and temporal scaling. Science 222, 159-162. https://doi.org/10.11 26/science.222.4620.159

Goswami,A., 2006. Cranial modularity shifts during mammalian evolution. The American Naturalist 168, 270-280. https://doi.org/10.1086/505758

Goswami A., Watanabe A., Felice R.N., Bardua C., Fabre A.C., Polly P.D., 2019. High-density morphometric analysis of shape and integration: the good, the bad, and the not-really-a-problem. Integrative and Comparative Biology 59, 669-683. https://doi. org/10.1093/icb/icz120

Gower J.C., 1975. Generalized procrustes analysis. Psychometrika 40, 33-51. https://doi.org/10.1007/BF02291478

Hanot P., Herrel A., Guintard C., Cornette R., 2018. The impact of artificial selection on morphological integration in the appendicular skeleton of domestic horses. Journal of Anatomy 232, 657-673. https://doi.org/10.1111/joa.12772

Hansen T.F., 1997. Stabilizing selection and the comparative analysis of adaptation. Evolution 51, 1341-1351. https://doi.or g/10.1111/j.1558-5646.1997.tb01457.x

Hansen T.F. 2012. Adaptive landscapes and macroevolutionary dynamics. In: Svennson E., Calsbeek R. (Eds), The Adaptive Landscape in Evolutionary Biology. Oxford University Press, Oxford, pp. 205-226. https://doi.org/10.1093/acprof:oso/97801 99595372.003.0013

Harmon L.J., Losos J.B., Jonathan Davies T., Gillespie R.G., Gittleman J.L., Bryan Jennings W., Kozak K.H., McPeek M.A., Moreno-Roark F., Near T.J., 2010. Early bursts of body size and shape evolution are rare in comparative data. Evolution: International Journal of Organic Evolution 64, 2385-2396. ht tps://doi.org/10.1111/j.1558-5646.2010.01025.x

Harmon L.J., Schulte J.A., Larson A., Losos J.B., 2003. Tempo and mode of evolutionary radiation in iguanian lizards. Science 301, 961-964. https://doi.org/10.1126/science.1084786

Hautmann M., 2020. What is macroevolution? Palaeontology 63, 1-11. https://doi.org/10.1111/pala.12465

Heers A.M., Dial K.P., 2015. Wings versus legs in the avian bauplan: development and evolution of alternative locomotor strategies. Evolution 69, 305-320. https://doi.org/10.1111/evo .12576

Jablonski D., 2005. Mass extinctions and macroevolution. Paleobiology 31, 192-210. https://doi.org/10.1666/0094-8373 (2005)031[0192:MEAM]2.0.CO;2 
Jablonski D., 2008. Biotic interactions and macroevolution: extensions and mismatches across scales and levels. Evolution: International Journal of Organic Evolution 62, 715-739. https: //doi.org/10.1111/j.1558-5646.2008.00317.x

Jarvis E.D., Mirarab S., Aberer A.J., Li B., Houde P., Li C., Ho S.Y.W., Faircloth B.C., Nabholz B., J.T. Howard., 2014. Whole-genome analyses resolve early branches in the tree of life of modern birds. Science 346, 1320-1331. https://doi.org/ $10.1126 /$ science. 1253451

Jetz W., Thomas G.H., Joy J.B., Hartmann K., Mooers A.O., 2012. The global diversity of birds in space and time. Nature 491, 444-448. https://doi.org/10.1038/nature11631

Klingenberg C.P., 2010. Evolution and development of shape: integrating quantitative approaches. Nature Reviews Genetics 11, 623-635. https://doi.org/10.1038/nrg2829

Klingenberg C.P., J. Marugán-Lobón., 2013. Evolutionary covariation in geometric morphometric data: analyzing integration, modularity, and allometry in a phylogenetic context. Systematic Biology 62, 591-610. https://doi.org/10.1038/nrg2829

Kulemeyer C., Asbahr K., Gunz P., Frahnert S., Bairlein F., 2009. Functional morphology and integration of corvid skulls a 3D geometric morphometric approach. Frontiers in Zoology 6, 2. https://doi.org/10.1186/1742-9994-6-2

Livezey B.C., Zusi R.L., 2006. Higher-Order Phylogeny of Modern Birds (Theropoda, Aves: Neornithes) Based on Comparative Anatomy. 1, Methods and Characters. Carnegie Museum of Natural History 37, 1-556. https://doi.org/10.2992/01459058(2006)37[1:PON]2.0.CO;2

Livezey B.C., Zusi R.L., 2007. Higher-order phylogeny of modern birds (Theropoda, Aves: Neornithes) based on comparative anatomy. II. Analysis and discussion. Zoological Journal of the Linnean Society 149, 1-95. https://doi.org/10.1111/j.10963642.2006.00293.x

Losos J.B., Mahler D.L., 2010. Adaptive radiation: the interaction of ecological opportunity, adaptation, and speciation. In Bell MA., Futuyma D.J., Eanes W.F., Levinton J.S. (Eds.), Evolution after Darwin: the first 150 years. Sinauer, Sunderland, MA, pp. 381-420.

Michaud M., Veron G., Fabre A., 2020. Phenotypic integration in feliform carnivores: covariation patterns and disparity in hypercarnivores versus generalists. Evolution, In Press. https: //doi.org/10.1111/evo.14112

Navalón G., Marugán-Lobón J., Bright J. A., Cooney C. R., Rayfield E.J., 2020. The consequences of craniofacial integration for the adaptive radiations of Darwin's finches and Hawaiian honeycreepers. Nature Ecology \& Evolution 4, 270-278. https://doi.org/10.1038/s41559-019-1092-y

Nudds R.L., Dyke G.J., Rayner J.M.V., 2007. Avian brachial index and wing kinematics: putting movement back into bones. Journal of Zoology, 272, 218-226. https://doi.org/10.1111/j.1 469-7998.2006.00261.x
Oliveros C.H., Field D.J., Ksepka D.T., Barker F.K., Aleixo A., Andersen M.J., Alström P., Benz B.W., Braun E.L., Braun M.J., 2019. Earth history and the passerine superradiation. Proceedings of the National Academy of Sciences 116, 7916-7925. https://doi.org/10.1073/pnas.1813206116

Olson E.C., Miller R.L. 1952. Morphological Integration. University of Chicago Press, Chicago.

Paluh D.J., Stanley E.L., Blackburn D.C., 2020. Evolution of hyperossification expands skull diversity in frogs. Proceedings of the National Academy of Sciences 117, 8554-8562. https: //doi.org/10.1073/pnas.2000872117

Pennell M.W., Harmon L.J., 2013. An integrative view of phylogenetic comparative methods: connections to population genetics, community ecology, and paleobiology. Annals of the New York Academy of Sciences, 1289, 90-105. https://doi.org/10.1111/nyas.12157

Pigot A.L., Sheard C.,. Miller E.T, Bregman T.P., Freeman B.G., Roll U., Seddon N., Trisos C.H., Weeks B.C., Tobias J.A., 2020. Macroevolutionary convergence connects morphological form to ecological function in birds. Nature Ecology \& Evolution 4, 1-10. https://doi.org/10.1038/s41559-019-1070-4

Proctor N., Lynch P., 1993. Manual of Ornithology : Avian Structure and Function. Yale University Press, New Haven.

Prum R.O., Berv J.S., Dornburg A., Field D.J., Townsend J.P., Lemmon E.M., Lemmon A.R., 2015. A comprehensive phylogeny of birds (Aves) using targeted next-generation DNA sequencing. Nature 526, 569-573. https://doi.org/10.1038/natu re 15697

Randau M., Goswami A., 2018. Shape covariation (or the lack thereof) between vertebrae and other skeletal traits in felids: the whole is not always greater than the sum of parts. Evolutionary Biology 45, 196-210. https://doi.org/10.1007/s11692-017-94 43-6

Rohlf F.J., Slice D., 1990. Extensions of the Procrustes method for the optimal superimposition of landmarks. Systematic Biology 39, 40-59. https://doi.org/10.2307/2992207

Rohlf F. J., Marcus L.F., 1993. A revolution morphometrics. Trends in Ecology \& Evolution 8, 129-132. https://doi.org/10. 1016/0169-5347(93)90024-J

Schluter D., 2000. The Ecology of Adaptive Radiation. Oxford University Press, Oxford.

Schneider C.A., Rasband W.S., Eliceiri K.W., 2012. NIH Image to ImageJ: 25 years of image analysis. Nature Methods 9, 671-675. https://doi.org/10.1038/nmeth.2089

Segall M., Herrel A., Godoy-Diana R.., 2019. Hydrodynamics of frontal striking in aquatic snakes: drag, added mass, and the possible consequences for prey capture success. Bioinspiration \& Biomimetics 14, 36005. https://doi.org/10.1088/1748-3190/ ab0316

Segall M., Cornette R., Fabre A.-C., Godoy-Diana R., Herrel A., 2016. Does aquatic foraging impact head shape evolution 
in snakes? Proceedings of the Royal Society B: Biological Sciences 283, 20161645. https://doi.org/10.1098/rspb.2016.16 45

Serrano F.J., Costa-Pérez M., Navalón G., Martín-Serra A., 2020. Morphological Disparity of the Humerus in Modern Birds. Diversity 12, 173. https://doi.org/10.3390/d12050173

Shatkovska O.V, Ghazali M., Mytiai I.S., Druz N., 2018. Size and shape correlation of birds' pelvis and egg: Impact of developmental mode, habitat, and phylogeny. Journal of Morphology 279, 1590-1602. https://doi.org/10.1002/jmor.20888

Silvestro D., Antonelli A., Salamin N., Quental T.B., 2015. The role of clade competition in the diversification of North American canids. Proceedings of the National Academy of Sciences 112, 8684-8689. https://doi.org/10.1073/pnas.1502 803112

Simpson G.G. 1944. Tempo and Mode in Evolution. Columbia University Press, New York.

Simpson G.G. 1953. The Major Features of Evolution. Columbia University Press, New York. https://doi.org/10.7312/simp937 64

Tokita M., Yano W., James H.F., Abzhanov A., 2017. Cranial shape evolution in adaptive radiations of birds: comparative morphometrics of Darwin's finches and Hawaiian honeycreepers. Philosophical Transactions of the Royal Society B: Biological Sciences 372, 20150481. https://doi.org/10.1098/rstb.2015. 0481

Venditti C., Meade A., Pagel M., 2011. Multiple routes to mammalian diversity. Nature 479, 393-396. doi: 10.1038/nature10516. https://doi.org/10.1038/nature10516

Vermeij G.J., 1973. Biological versatility and earth history. Proceedings of the National Academy of Sciences 70, 1936-1938. https://doi.org/10.1073/pnas.70.7.1936

Vrba E.S., 1983. Macroevolutionary trends: new perspectives on the roles of adaptation and incidental effect. Science 221, 387-389. https://doi.org/10.1126/science.221.4608.387

Watanabe A., Fabre A.C., Felice R.N., Maisano J.A., Müller J., Herrel A., Goswami A., 2019. Ecomorphological diversification in squamates from conserved pattern of cranial integration. Proceedings of the National Academy of Sciences 116, 14688-14697. https://doi.org/10.1073/pnas.1820967116

Wilman H., Belmaker J., Simpson J., De La Rosa C., Rivadeneira M.M., Jetz W., 2014. EltonTraits 1.0: Species-level foraging attributes of the world's birds and mammals. Ecology 95, 2027. https://doi.org/10.1890/13-1917.1

Wright N.A., Steadman D.W., Witt C.C., 2016. Predictable evolution toward flightlessness in volant island birds. Proceedings of the National Academy of Sciences 113, 4765-4770. https://doi.org/10.1073/pnas.1522931113

Yoder J.B., Clancey E., Des Roches S., Eastman J.M., Gentry L., Godsoe W., Hagey T.J., Jochimsen D., Oswald B.P., Robertson J., 2010. Ecological opportunity and the origin of adaptive radiations. Journal of Evolutionary Biology 23, 1581-1596. https://doi.org/10.1111/j.1420-9101.2010.02029.x

Zusi R.L., 1993. Patterns of Diversity in the Avian Skull. In: Hanken J., Hall B.K. (Eds.), The skull. Vol. 2. The University of Chicago Press, Chicago, pp. 391-437. 